\title{
$2-2-2018$
}

\section{The time has come for dimensional personality disorder diagnosis}

Christopher J. Hopwood

chopwoodmsu@gmail.com

Roman Kotov

Robert F. Krueger

David Watson

Thomas A. Widiger

See next page for additional authors

Follow this and additional works at: https://scholarworks.wm.edu/aspubs

\section{Recommended Citation}

Hopwood, C. J., Kotov, R., Krueger, R. F., Watson, D., Widiger, T. A., Althoff, R. R., ... \& Bornovalova, M. A. (2018). The time has come for dimensional personality disorder diagnosis. Personality and mental health, 12(1), 82-86.

This Article is brought to you for free and open access by the Arts and Sciences at W\&M ScholarWorks. It has been accepted for inclusion in Arts \& Sciences Articles by an authorized administrator of W\&M ScholarWorks. For more information, please contact scholarworks@wm.edu. 


\section{Authors}

Christopher J. Hopwood, Roman Kotov, Robert F. Krueger, David Watson, Thomas A. Widiger, Robert R. Althoff, Emily B. Ansell, Bo Bach, R. Michael Bagby, Mark A. Blais, Marina A. Bornovalova, Michael Chmielewski, David C. Cicero, Christopher Conway conway@wm.edu, Barbara De Clercq, Filip De Fruyt, Anna R. Docherty, Nicholas R. Eaton, John F. Edens, Miriam K. Forbes, Kelsie T. Forbush, Michael P. Hengartner, Masha Y. Ivanova, Daniel Leising, and W. John Livesley 


\section{Personality and Mental Health}

Personality and Mental Health

12: 82-86 (2018)

Published online 11 December 2017 in Wiley Online Library

(wileyonlinelibrary.com) DOI 10.1002/pmh.1408

\section{Commentary}

\section{The time has come for dimensional personality disorder diagnosis}

CHRISTOPHER J. HOPWOOD ${ }^{1}$, ROMAN KOTOV ${ }^{2}$, ROBERT F. KRUEGER ${ }^{3}$, DAVID WATSON ${ }^{4}$, THOMAS A. WIDIGER ${ }^{5}$, ROBERT R. ALTHOFF ${ }^{6}$, EMILY B. ANSELL ${ }^{7}$, BO BACH $^{8}$, R. MICHAEL BAGBY ${ }^{9}$, MARK A. BLAIS ${ }^{10}$, MARINA A. BORNOVALOVA ${ }^{11}$, MICHAEL CHMIELEWSKI ${ }^{12}$, DAVID C. CICERO ${ }^{13}$, CHRISTOPHER CONWAY ${ }^{14}$, BARBARA DE CLERCQ ${ }^{15}$, FILIP DE FRUYT ${ }^{15}$, ANNA R. DOCHERTY ${ }^{16}$, NICHOLAS R. EATON ${ }^{2}$, JOHN F. EDENS ${ }^{17}$, MIRIAM K. FORBES ${ }^{3}$, KELSIE T. FORBUSH ${ }^{18}$, MICHAEL P. HENGARTNER ${ }^{19}$, MASHA Y. IVANOVA ${ }^{6}$, DANIEL LEISING ${ }^{20}$, W. JOHN LIVESLEY ${ }^{21}$, MARK R. LUKOWITSKY ${ }^{22}$, DONALD R. LYNAM ${ }^{23}$, KRISTIAN E. MARKON ${ }^{24}$, JOSHUA D. MILLER ${ }^{25}$, LESLIE C. MOREY ${ }^{17}$, STEPHANIE N. MULLINS-SWEATT ${ }^{26}$, J. HANS ORMEL $^{27}$, CHRISTOPHER J. PATRICK ${ }^{28}$, AARON L. PINCUS ${ }^{29}$, CAMILO RUGGERO $^{30}$ DOUGLAS B. SAMUEL ${ }^{23}$, MARTIN SELLBOM ${ }^{31}$, TIM SLADE ${ }^{32}$, JENNIFER L. TACKETT ${ }^{33}$, KATHERINE M. THOMAS ${ }^{23}$, TIMOTHY J. TRULL ${ }^{34}$, DAVID D. VACHON ${ }^{35}$, IRWIN D. WALDMAN ${ }^{36}$, MONIKA A. WASZCZUK ${ }^{2}$, MARK H. WAUGH ${ }^{37}$, AIDAN G. C. WRIGHT ${ }^{38}$, MATHEW M. YALCH ${ }^{39}$, DAVID H. ZALD ${ }^{40}$ AND JOHANNES ZIMMERMANN ${ }^{41}$, ${ }^{1}$ University of California, Davis, Davis California, USA; ${ }^{2}$ Stony Brook University, Stony Brook, New York, USA; ${ }^{3}$ University of Minnesota, Minneapolis, MN, USA; ${ }^{4}$ University of Notre Dame, South Bend, IN, USA; ${ }^{5}$ University of Kentucky, Lexington, KY, USA; ${ }^{6}$ University of Vermont, Burlington, VT, USA; ${ }^{7}$ Syracuse University, Syracuse, NY, USA; ${ }^{8}$ Region Zealand Psychiatry, Roskilde, Denmark; ${ }^{9}$ University of Toronto, Scarborough, Toronto, ON, Canada; ${ }^{10}$ Harvard Medical School, Boston, MA, USA; ${ }^{11}$ University of South Florida, Tampa, Florida, USA; ${ }^{12}$ Southern Methodist University, Dallas, TX, USA; ${ }^{13}$ University of Hawai'i, Honolulu, HI, USA; ${ }^{14}$ College of William \& Mary, Williamsburg, VA, USA; ${ }^{15}$ University of Ghent, Ghent, Belgium; ${ }^{16}$ University of Utah, Salt Lake City, UT, USA; ${ }^{17}$ Texas A\&M University, College Station, TX, USA; ${ }^{18}$ University of Kansas, Lawrence, KS, USA; ${ }^{19}$ Zurich University of Applied Sciences, Zurich, Switzerland; ${ }^{20}$ Technische Universität Dresden, Dresden, Germany; ${ }^{21}$ University of British Columbia, Vancouver, BC, Canada; ${ }^{22}$ Albany Medical College, Albany, NY, USA; ${ }^{23}$ Purdue University, West Lafayette, IN, USA; ${ }^{24}$ University of Iowa, Iowa City, IA, USA; ${ }^{25}$ University of Georgia, Athens, GA, USA; ${ }^{26}$ Oklahoma State University, Stillwater, OK, USA; ${ }^{27}$ University of Groningen, Groningen, the Netherlands; ${ }^{28}$ Florida State University, Tallahassee, FL, USA; ${ }^{29}$ Pennsylvania State University, State College, PA, USA; ${ }^{30}$ University of North Texas, Dallas, TX, USA; ${ }^{31}$ University of Otago, Otago, New Zealand; ${ }^{32}$ University of New South Wales, Kensington, New South Wales, Australia; ${ }^{33}$ Northwestern University, Evanston, IL, USA; ${ }^{34}$ University of Missouri, 
Columbia, MO, USA; ${ }^{35}$ McGill University, Montreal, Quebec, CA; ${ }^{36}$ Emory University, Atlanta, GA, USA; ${ }^{37}$ University of Tennessee, Knoxville, TN, USA; ${ }^{38}$ University of Pittsburgh, Pittsburgh, PA, USA; ${ }^{39}$ Marian University, Indianapolis, IN, USA; ${ }^{40}$ Vanderbilt University, Nashville, TN, USA; ${ }^{41}$ Psychologische Hochschule Berlin, Berlin, Germany

The committee revising the ICD-11 Mental or Behavioural Disorders section 'Personality Disorders and Related Traits' has proposed replacing categorical personality disorders with a severity gradient ranging from personality difficulties to severe personality disorder and five trait domains: negative affectivity, dissocial, disinhibition, anankastic and detachment ${ }^{1}$. While acknowledging that there are multiple potential pathways for moving toward a more evidence-based and clinically useful scheme for classifying personality dysfunction, we applaud and support the proposed transition from a categorical model of personality disorder types, which has proven to be empirically problematic and of limited clinical utility, to a dimensional model of personality disorder that has considerable connection to scientific evidence and potential for clinical application.

There is no evidence supporting the hypotheses that personality disorders are categorical ${ }^{2,3}$ or that there are 10 (or any other number of) discrete types of personality disorder ${ }^{4}$. Well-established problems with categorical personality disorder diagnosis such as low reliability, diagnostic comorbidity and within-disorder heterogeneity complicate research and treatment ${ }^{5}$. There are no validated interventions for most of the categorical personality disorders, and although several psychotherapies from different theoretical perspectives have been developed for borderline personality disorder that have evidence of moderate efficacy, none have proven to be relatively more effective than any of the others ${ }^{6}$. Evidence for treatment mechanisms is sparse, and there is no evidence that existing approaches have specific efficacy for borderline personality disorder as opposed to general efficacy for a variety of psychiatric difficulties?

In contrast, there is a vast body of empirical literature supporting dimensional models of personality disorder that are closely aligned with the proposed model ${ }^{8-11}$, in addition to the emerging body of work on the specific dimensions proposed for ICD-11 ${ }^{12-19}$. The ICD-11 proposal has two elements. The severity dimension has ties to the psychodynamic tradition ${ }^{20,21}$, which has historically been at the forefront of personality disorder classification, and aligns with a number of empirical efforts to quantify general personality dysfunction (e.g. ${ }^{22-27}$ ). Research demonstrates that much of the predictive and prognostic value in personality disorder data can be derived from such a dimension 28 .

The personality trait model proposed for ICD-11 resembles other dimensional models of personality such as the Five-Factor Model or the DSM-5 Alternative Model for Personality Disorders $16,29,30$. Although there are some important differences between the ICD-11 proposal and these other models that will be adjudicated by future research, the more important point at this stage is that evidence consistently supports the validity of dimensional trait models for describing individual differences in personality. In contrast to the categorical model of personality disorder types, there is a large literature on the genetic underpinnings, cross-cultural validity, course, correlates and measurement of broad personality traits ${ }^{11,31}$. Dimensional models also address issues such as comorbidity and heterogeneity in a direct and empirically tractable manner ${ }^{8}$; recapture but empirically reorganize the information provided by personality disorder types $^{32}$; and have considerable potential for guiding and tracking treatment ${ }^{33,34}$. We would highlight that research has repeatedly shown that the borderline personality disorder construct in particular can be accounted for by empirically derived dimensions of personality traits and functioning ${ }^{35-40}$.

Nevertheless, some people in the field continue to argue in favour of personality diagnosis by categorical types. We are concerned about the 
implications of retaining a categorical system that has been so thoroughly shown to be empirically and clinically problematic. It is very difficult to justify allocating resources toward continued research on an approach that has proven to be fundamentally flawed, as opposed to a dimensional model that points to exciting new avenues for research on aetiology, mechanisms and treatment (e.g. ${ }^{41}$ ). We are likewise concerned about the implications that retaining a demonstrably problematic model has for patients' lives. It would be very unsettling to be told that one's problems are due to a specific medical condition, only to learn later that the supposed condition had been abandoned by the medical community. It is probably already confusing for patients, who might discover via an internet search on their personality diagnosis that much of the field does not believe such a disorder actually exists. It would be far preferable to be straightforward with our patients about what we know and do not know regarding personality and its related problems than to label them with legacy diagnoses that will not stand the test of time.

Reasonable concerns have been expressed about challenges associated with the transition from a categorical to a dimensional model of personality disorder. Such concerns need to be balanced against several field surveys that show that a majority of clinicians and researchers support the transition to a more dimensional, evidence-based framework ${ }^{42-44}$. We acknowledge that the transition to a dimensional model needs to be thoughtful with regard to issues such as third-party reimbursement. Moreover, we recognize that legal, community mental health and other systems will need to be educated regarding how to translate from the old system to the new. However, we do not believe that these practical issues provide a compelling rationale for retaining a system that does not effectively capture individual differences in patients' personality difficulties. In contrast, moving forward with an evidence-based framework for diagnosing personality disorders has significant potential to stimulate research that can lead to new treatments and aetiological models that will ultimately reduce the burden of personality disorders on patients, families and society. The changes proposed for ICD-11 also provide a generative model for conceptualizing the meta-structure of psychopathology. Indeed, there are clear phenotypic and genetic links between the dimensions proposed for ICD-11 and a number of mental health conditions beyond personality disorders 45,46 .

Past scientists believed that the sun revolved around the earth, the brain was organized according to the principles of phrenology, and spirits were responsible for psychiatric problems. It is a testament to science that these views gave way to a more accurate model of nature. The new perspectives that replaced them contributed to major advancements in astronomy, neuroscience and mental health. Likewise, the evidence is clear that personality disorders do not exist as 10 discrete types. The categorical model has become a hindrance to research and practice. As an example, see the unfortunate outcome of the DSM-5 revision process, in which a model that is not supported by evidence or the majority of the field was retained as the official diagnostic scheme despite the viable alternative proposed by the Personality and Personality Disorders Work Group, published in Section III of DSM-5. It is time for the field to transition to a model that fits research data and clinical reality. The ICD-11 proposal connects psychiatric classification of personality disorder manifestations with scientific evidence. The proposed changes would enhance diagnostic efficiency and patient care while spurring research that can further improve the assessment and treatment of psychopathology. As clinicians and researchers who have dedicated our careers to understanding and helping people with personality pathology, we urge the ICD-11 PD work group to remain committed to an evidence-based revision of personality disorder diagnosis.

\section{References}

1. Tyrer P, Crawford M, Mulder R. Reclassifying personality disorders. Lancet 2011; 377: 1814-5. 
2. Clark LA. Assessment and diagnosis of personality disorder: perennial issues and emerging conceptualization. Annu Rev Psychol 2007; 58: 227-58.

3. Trull TJ, \& Durrett CA. Categorical and dimensional models of personality disorder. Annu Rev Clin Psychol 2005; $1: 355-80$.

4. Anderson J, Snider S, Sellbom S, Krueger RF, Hopwood CJ. A comparison of the DSM-5 section II and section III personality disorder structures. Psychiatry Res 2014; 216: 363-72.

5. Widiger TA, \& Samuel DB. Diagnostic categories or dimensions? A question for the diagnostic and statistical manual of mental disorders, fifth edition. J Abnorm Psychol 2005; 114: 494-504.

6. Cristia IA, Gentili C, Cotet CD, Palomba D, Barbui C, Cuijpers P. Efficacy of psychotherapies for borderline personality disorder: a systematic review and meta-analysis. JAMA Psychiat 2017; 74: 319-28.

7. Bateman AW, Gunderson J, Mulder R. Treatment of personality disorder. Lancet 2015; 385: 735-43.

8. Krueger RF, Markon KE. The role of the DSM-5 personality trait model in moving toward a quantitative and empirically based approach to classifying personality and psychopathology. Annu Rev Clin Psychol 2014; 10: 477-501.

9. Markon KE, \& Krueger RF. Delineating the structure of normal and abnormal personality: an integrative hierarchical approach. J Pers Soc Psychol 2005; 88: 139-57.

10. Morey LC, Hopwood CJ, Gunderson JG, Skodol AE, Shea MT, Yen $S$ et al. Comparison of alternative models for personality disorders. Psychol Med 2007; 37: 983-94.

11. Widiger TA, \& Trull TJ. Plate tectonics in the classification of personality disorder. American Psychologist 2007; 62: 71-83.

12. Kim Y-R, Blashfield R, Tyrer P, Hwang S, Lee H. Field trial of a putative research algorithm for the diagnosis of ICD-11 personality disorders in psychiatric patients: 1. severity of personality disturbance. Personality and Mental Health 2014; 8: 67-78.

13. Kim Y-R, Tyrer P, Kim H-S, Kim S-G, Hwang ST, Lee G-Y et al. Preliminary field trial of a computer algorithm for diagnosing ICD-11 personality disorders in psychiatric patients: 2. proposed trait domains. Personality and Mental Health 2015; 9: 298-307.

14. Kim YR, Tyrer P, Lee HS, Kim SG, Connan F, Kinnaird $\mathrm{E}$ et al. Schedule for personality assessent from notes and documents (SPAN-DOC): preliminary validation, links to the ICD-11 classification of personality disorder, and use in eating disorders. Personality and Mental Health 2016; 10: 106-17.

15. Mulder RT, Horwood J, Tyrer P, Carter J, Joyce PR. Validating the proposed ICD-11 domains. Personality and Mental Health 2016; 10: 84-95.
16. Oltmanns JR, \& Widiger TA. A self-report measure of the ICD-11 dimensional trait model proposal: the personality inventory for ICD-11. Psychol Assess in press.

17. Tyrer P, Crawford M, Sanatinia R, Tyrer H, Cooper S, Muller-Pollard C et al. Preliminary studies of the ICD11 classification of personality disorder in practice. Personality and Mental Health 2014; 8: 254-63.

18. Tyrer P, Tyrer H, Yang M, Guo B. Long-term impact of temporary and persistent personality disorder on anxiety and depressive disorders. Personality and Mental Health 2016a; 10: 76-83.

19. Tyrer P, Wang D, Tyrer H, Crawford M, Cooper S. Dimensions of dependence and their influence on the outcome of cognitive behavior therapy for health anxiety: randomized controlled trial. Personality and Mental Health 2016b; 10: 96-105.

20. Bender DS, Morey LC, Skodol AE. Toward a model for assessing level of personality functioning in DSM-5, part 1: a review of theory and methods. J Pers Assess 2011; 93: $332-46$.

21. Kernberg OF. Severe Personality Disorders: Psychotherapeutic Strategies. New Haven, CT: Yale University Press, 1984.

22. Bornstein RF. Reconceptualizing personality disorder diagnosis in the DSM-V: the discriminant validity challenge. Clinical Psychology: Science and Practice 1998; 5: $333-43$.

23. Hopwood CJ, Malone JC, Ansell EB, Sanislow CA, Grilo CM, McGlashan TH et al. Personality assessment in DSM-V: empirical support for rating severity, style, and traits. J Pers Disord 2011; 25: 305-20.

24. Livesley WJ. Suggestions for a framework for an empirically based classification of personality disorder. Can J Psychiatry 1998; 43: 137-47.

25. Morey LC. Development and initial evaluation of a self-report form of the DSM-5 level of personality functioning scale. Psychol Assess in press.

26. Morey LC, Berghuis H, Bender DS, Verheul R, Krueger RF, Skodol AE. Twoard a model for assessing level of personality functioning in DSM-5, part II: empirical articulation of a core dimension of personality pathology. J Pers Assess 2011; 93: 346-53.

27. Parker G. The etiology of personality disorders: a review and consideration of research models. J Pers Disord 1997; 11: 345-69.

28. Wright AGC, Hopwood CJ, Skodol AE, Morey LC. Longitudinal validation of general and specific structural features of personality pathology. J Abnorm Psychol 2016; 125: 1120-34.

29. Bach B, Sellbom M, Kongerslev M, Simonsen E, Krueger RF, Mulder R. Deriving ICD-11 personality disorder domains from DSM-5 traits: initial attempt to harmonize two diagnostic systems. Acta Psychiatr Scand in press. 
30. Widiger TA, \& Simonsen E. Alternative dimensional models of personality disorder: finding a common ground. J Pers Disord 2005; 19: 110-30.

31. Soto CJ, \& Tackett JL. Personality traits in childhood and adolescence: structure, development, and outcomes. Current Directions in Psychological Science 2015; 24: 358-62.

32. Miller JD, Few LR, Lynam DR, MacKillop J. Pathological personality traits can capture DSM-IV personality disorder types. Personality Disorders: Theory, Research, and Treatment 2015; 6: 32-40.

33. Hopwood CJ, Zimmermann J, Pincus AL, Krueger RF. Connecting personality structure and dynamics: toward a more evidence-based and clinically useful diagnostic scheme. J Pers Disord 2015; 29: 431-48.

34. Roberts BW, Luo J, Briley DA, Chow P, Su R, Hill PL. A systematic review of personality trait change through intervention. Psychol Bull 2017; 143: 117-41.

35. Bornovalova MA, Hicks BM, Patrick CJ, Iacono WG, McGue M. Development and validation of the Minnesota borderline personality disorder scale (MBPD). Assessment 2011; 18: 234-52.

36. Miller JD, Morse JQ, Nolf K, Stepp SD, Pilkonis PA. Can DSM-IV borderline personality disorder be diagnosed via dimensional personality traits? Implications for the DSM-5 personality disorder proposal. J Abnorm Psychol 2012; 121: 944-50.

37. Sellbom M, Sansone RA, Songer DA, Anderson JL. Convergence between DSM-5 section II and section III diagnostic criteria for borderline personality disorder. Australian and New Zealand Journal of Psychiatry 2014; 48: 325-32.

38. Sharp C, Wright AGC, Fowler JC, Freuh C, Allen JG, Oldham $\mathrm{J}$ et al. The structure of personality pathology: both general ('g') and specific ('s') factors? J Abnorm Psychol 2015; 124: 387-98 http://www.personalityprocesses.com/s/ Sharp-Wright-et-al-in-press-Strucutre-of-PP.pdf.

39. Trull TJ, Widiger TA, Lynam DR, Costa PT, Jr. Borderline personality disorder from the perspective of general personality functioning. J Abnorm Psychol 2003; 112: 193-202.

40. Wright AGC, Hopwood CJ, Zanarini MC. Associations between changes in normal personality traits and borderline personality disorder symptoms over 16 years. Personality Disorders: Theory, Research, and Treatment 2015; 6: $1-11$.

41. Cuthbert BN. The RDoC framework: facilitating transition from ICD/DSM to dimensional approaches that integrate neuroscience and psychopathology. World Psychiatry 2014; 13: 28-35.

42. Bernstein DP, Iscan C, Maser J, Boards of Directors of the Association for Research in Personality Disorders and Interntional Society for the Study of Personality Disorders. Opinions of personality disorder experts regarding the DSM-IV personality disorder classification system. J Pers Disord 2007; 21: 536-51.

43. Keeley J, Reed G, Roberts M, Evans S, Medina-Mora M, Robles $\mathrm{R}$ et al. Developing a science of clinical utility in diagnostic classification systems field study strategies for ICD-11 mental and behavioral disorders. American Psychologist 2016; 71: 3-16.

44. Morey LC, Skodol AE, Oldham JM. Clinician judgments of clinical utility: a comparison of DSM-IV-TR personality disorders and the alternative model for DSM-5 personality disorders. J Abnorm Psychol 2014; 123: 398-405.

45. Kotov R, Gamez W, Schmidt F, Watson D. Linking big personality traits to anxiety, depressive, and substance use disorders: a meta-analysis. Psychol Bull 2010; 136: 768-821.

46. Kotov R, Krueger RF, Watson D, Achenbach TM, Althoff RR, Bagby $M$ et al. The hierarchical taxonomy of psychopathology (HiTOP): a dimensional alternative to traditional nosologies. J Abnorm Psychol in press.

Address correspondence to: Christopher J. Hopwood, University of California, Davis, Davis CA, USA. Email: chopwoodmsu@gmail.com 